\title{
Oscar Tovar Serpa Doctor en Ciencias Biológicas (1923 - 2009)
}

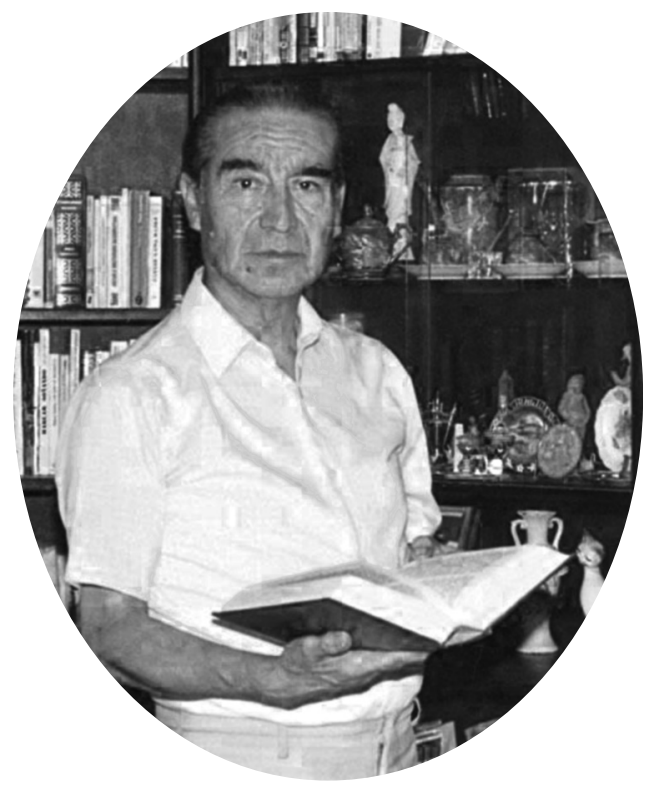

El maestro de las gramíneas (poáceas) del Perú, Dr. Oscar Tovar, nació el 25 de octubre de 1923 en el pueblo de Conaica (Huancavelica) y falleció en la ciudad de Lima el 27 de octubre de 2009. Sus vivencias en el Ande peruano sirvieron para motivar sus estudios universitarios de biología en la Universidad Nacional Mayor de San Marcos, gracias a los cuales exploró y estudió metódicamente la flora peruana.

Sus investigaciones taxonómicas en la familia Asteraceae, y en particular la revisión del género Chuquiraga le permitieron obtener su doctorado en 1955 en la Universidad Nacional Mayor de San Marcos. Su mayor producción científica en taxonomía estuvo en el estudio de las Asteráceas y Poáceas, entre las que destacan la revisión de las especies peruanas de los géneros Flotovia (1953), Perezia (1955), Calamagrostis (1960), Poa (1965) y Festuca (1972).

Desde los inicios de sus investigaciones botánicas el Dr. Tovar estuvo vinculado al Museo de Historia Natural de la misma Universidad. Junto a la Dra. Emma Cerrate y al Dr. Ramón Ferreyra contribuyó al crecimiento y fortalecimiento del Herbario San Marcos desde la década de los 1950 y dedicó su vida al fortalecimiento de este herbario con sus innumerables colecciones botánicas.

Desde 1970 fue profesor principal a Dedicación Exclusiva del Departamento Académico de Ciencias Biológicas, en el cual asumió la responsabilidad como Director del Programa Académico de 1971 a 1976; también fue primer director del Instituto de Investigación de Ciencias Biológicas Antonio Raimondi (ICBAR) de 1977 - 1979.

En reconocimiento a su fecunda actividad de investigación en 1986 se le otorgó la condición de Profesor Emérito. Aun después de su jubilación continuó laborando en el museo dedicado a sus investigaciones, asesorando tesis de posgrado y publicando hasta tres meses antes de su sensible fallecimiento.
Su innegable contribución a la flora andina está reflejada en las 59 especies nuevas que describiera, siete de ellas en la familia Asteraceae y 52 en las Poaceae; además de combinaciones nuevas (dos en cada una de esas familias citadas). Asimismo, más de 18 taxones en 8 familias botánicas distintas tienen en su epíteto el nombre del Dr. Oscar Tovar, como reconocimiento de otros botánicos a su trayectoria, entre ellas podemos citar a Nolana tovariana Ferreyra, Aequatorium tovarii H.Rob. \& Cuatrec., Liabum tovari Cabrera, Nototriche tovari Krapov., Axinea tovarii Wurdack, Piptochaetium tovarii Sanchez Vega, Solanum tovarii S. Knapp. Por ello, en reconocimiento a su experiencia y conocimiento de la flora, sus colegas de la Organización para la Flora Neotrópica lo incorporaron como miembro de la misma desde sus inicios en 1964.

El trabajo de campo en las diferentes regiones del Perú formó parte importante de las actividades del Dr. Tovar, a través de las cuales compiló sus observaciones sobre la distribución y características de la flora y vegetación, así como el estado de conservación de los ambientes naturales. Una de las expediciones que le brindo gratos recuerdos fue la de 1977, en la cual el Dr. Tovar, como contraparte de investigación de los desaparecidos botánicos norteamericanos Richard E. Schultes y Timothy Plowman, recolectaron a lo largo de la parte peruana del río Amazonas; resultado de esta expedición más de 1500 ejemplares de la misma forman parte de la colección del Herbario San Marcos. En la década de 1990 el Dr. Tovar con su espíritu explorador y de estudio continúo participo en los viajes de colectas del Centro de Datos para la conservación de la Universidad Nacional Agraria la Molina (UNALM).

El rico legado del Dr. Tovar se extiende también a las áreas de la biogeografía, florística y de la conservación. Como resultado de estas inquietudes científicas están sus publicaciones: Las Comunidades Vegetales de la Reserva Nacional de Vicuñas de Pampa Galeras (1973), la Ecomorfología de algunas Plantas de la 
Puna Central del Perú (1977), Vegetatio Andinae, I. Datos sobre las comunidades Vegetales Altoandinas de los andes Centrales del Perú (1982), Plantas Medicinales del Valle del Mantaro (2001), entre otras.

En 1993, el Dr. Tovar publicó su contribución más importante en la familia Poaceae, Las gramineas del Perú, en la cual reúne sus observaciones y estudios, de más de 35 años, en 156 géneros de esta diversa e importante familia botánica. Este trabajo se basó en los estudios que realizo tanto en el herbario San Marcos, como en los herbarios de la Smithsonian (a través de una beca de la Fundación Guggenheim) y del de la Universidad de Harvard de los Estados Unidos de Norteamérica.

La fructífera producción científica, digna a ser imitada, continuó hasta el 2009, cuando en agosto de ese año salió publicado Notas sobre las especies de los pastizales entre Iquitos y Nauta, Loreto, Perú.
La calidad humana, sencillez y el espíritu siempre crítico del Dr. Tovar sobre la realidad del Perú, sirvió a los que tuvimos la fortuna de conocerlo de valorar al científico y al ciudadano ejemplar. Esperamos que esta semblanza contribuya a resaltar los valores y las razones de estima y admiración por el Dr. Oscar Tovar. Al explorador y estudioso del Perú, que él recorrió animoso siempre, emprendedor y sin temor a las dificultades vaya este homenaje.

¡Descanse en paz, insigne maestro!

\section{Dra. Betty Millán}

Presidenta de la Sociedad Peruana de Botánica bmillans@gmail.com

\section{Dra. Blanca León}

Vice-presidenta de la Sociedad Peruana de Botánica blanca.leon@mail.utexas.edu

Mg. María Isabel la Torre

Tesorera de la Sociedad Peruana de Botánica marycano_11@yahoo.com 